\title{
A New Research Direction: Underwater Acoustic Signal Combined Processing Based on Multi-Field Coherence
}

\author{
Zhengxian Wei ${ }^{1}$, Min Song ${ }^{2 *}$ and Houbing Song ${ }^{3}$ \\ ${ }^{1}$ Systems Engineering Research Institute, China \\ ${ }_{2}^{2}$ Information Technology Center, Beijing Foreign Studies University, China \\ ${ }^{3}$ Department of Electrical, Computer, Software, and Systems Engineering, Embry-Riddle Aeronautical University, USA \\ Submission: January 10, 2019; Published: January 25, 2019 \\ Corresponding author: Min Song, Information Technology Center, Beijing Foreign Studies University, Beijing, China
}

\begin{abstract}
The $21^{\text {st }}$ century is considered the century of the ocean. There are many acoustic field effects distributed in ocean, including convergence zones, shadow zones, underwater acoustic channels and so on. Regarding the application of underwater acoustic networks, we point out that underwater acoustic signal combined processing based on multi-field coherence is a new research direction, then put forward scientific problems and research approaches for it. We hope that our opinion will guide more researchers to address the topic in order to jointly promote research in this field and obtain more valuable research results.
\end{abstract}

Keywords: Acoustic Multi-Field Effects; Coherence; Signal Combined Processing; Research Direction

\section{Introduction}

The low-cost and highly-reliable underwater acoustic network is an effective means of monitoring the marine environment, detecting seabed resources, searching in marine rescue operations, etc. $[1,2]$. There are many acoustic field effects distributed in the Pacific, Atlantic, Indian Ocean, etc., including convergence zones, shadow zones, deep sea acoustic channels and so on. The different sensor nodes of the network may be deployed in different acoustic field zones while adopting suitable working modes; for example, sensor nodes deployed in convergence zones adopt the "convergence zone working mode", while those deployed in the deep-sea acoustic channels adopt the "deep sea acoustic waveguide working mode". With the increase in the bandwidth and rate of underwater communication, it has become possible to carry out the combined processing of the acoustic signals of distributed nodes. Therefore, achieving processing gain of multi-field coherence and correlation through combined processing of different sensor node signals will become a new research direction.

\section{Key Scientific Problems for Signal Combined Proces- sing Based on Multi-Field Coherence}

It is well known that the time, spatial and frequency coherence properties and laws of acoustic effects form the foundation of signal processing. Many factors such as random fluctuations on sea surfaces, seabed unevenness, water body heterogeneity, uncertainty of ocean currents, temperature changeability and salinity changeability exist in different acoustic fields, which consequently result in significant differences in their time, spatial and frequency coherence properties. For example, the frequency interference structure, space and time correlation in convergence zones are significantly different from those in the shadow zones. To this end, how to scientifically and rationally hold on the time, spatial and frequency coherence properties and laws among multi-fields, how to carry out the single combined processing between different underwater acoustic network nodes which were deployed in different acoustic fields to achieve high gain is the scientific problem and should to be solved. For example, when the acoustic signals of a shadow zone and those of a convergence zone are processed together, it is necessary to determine whether any interference exists among them or through compensate and modified the phase and amplitude of the signal in order to observe the interference phenomenon.

\section{Research Approach}

The interference phenomenon is a unique characteristic of fluctuation. The coherence of an acoustic field manifests as the interference phenomenon of signal in the spatial, time and frequency. Great achievements have been made in research on 
the single acoustic field coherence effects. In 1982, S. D. Chuprov of Moscow State University [3], put forward the innovative and significant "Waveguide Invariant Theory". He first used the normal mode theory and ray acoustic theory to research the mechanism and depiction of interference fringe on the distancefrequency plane. He then pointed out that space-frequency interference fringes are formed by a group of normal mode model coherences with similar orders, and the slope is a scalar value $\beta$ that does not change with changes in the frequency or mode order number. He called value $\beta$ the "waveguide invariant" and demonstrated that the waveguide invariant describes the micro-structure characteristics of sound waves propagating in the ocean from a brand-new angle. At present, research on single acoustic field interference structures is gradually shifting from the macroscopic energy to the fine micro-structure $[4,5]$, and from the scalar sound pressure interference structure to the vector interference structure [6]. However, at present, no research has been conducted on the coherence properties and laws among different acoustics fields, and the signals combined processing of multi-field has not yet been achieved [7]. To implement signal combined processing based on multi-field coherence and obtain significant performance gain based on multi-fields effects with wide coverage of different sensor nodes in underwater acoustic network [8].

The following research directions should be explored:

A. Research should be conducted on the spatial correlations among different acoustic fields in typical environments $[9,10]$. Regarding the different acoustic field effects of convergence zones, deep sea acoustic channels, surface acoustic channels, shadow zones, etc., analyses should be carried out of the different acoustic field levels and vertical correlations, and such relationships among relevant acoustic parameters as sound velocity and spatial distance $[11,12]$. Theoretical models should be constructed according the spatial correlations among different acoustic fields, the internal relations and change laws of the spatial correlations of multi-fields should be identified and signals combined processing gain of different nodes should be further analyzed $[13,14]$.

B. Research should be conducted on the time, spatial and frequency interference structures among typical different acoustics fields [15]. Analyses should be carried out of the mechanisms of factors such as seabed terrain, underwater sound velocity distribution, etc. impact on the time, spatial and frequency interference structures among different acoustics fields, and research should be conducted on stable interference structures produced among different acoustics fields and the physical mechanisms that cause interference structures to change [16]. The distribution and robustness of interference structures under the coupling of different acoustics field should be analyzed, and the characteristics and laws models of time, spatial and frequency interference structures of multi-fields should be identified [17].
C. Research should be conducted on the relationship of physical characteristic parameters of the time, spatial and frequency interference structures among typical different acoustics fields [18]. Analyses should be made of the mechanisms of the time, spatial and frequency interference structure formation of multi-fields. Processing methods for improving the stability and tolerance of interference structures should be researched, and the physical characteristic parameters (such as waveguide invariants) of spatial and frequency interference structures among different acoustics fields and their representation models should be put forward [19].

D. Research should be conducted on the combined processing methods of the underwater acoustic signals of multi-fields, and relevant experiments should be carried out [20]. Sound sources and fixedly placed horizontal linear arrays and vertical linear arrays of sensor nodes should be used to carry out experiment in typical ocean environments, and the laws of the spatial and frequency interference structures of multi-fields verified, as well as the spatial correlation laws of multi-fields [21].

\section{Conclusion}

The $21^{\text {st }}$ century is considered the century of the ocean. Marine environmental monitoring, marine resource utilization, marine fishery and aquaculture have become important economic pillars in global economic development. Therefore, underwater acoustic signal combined processing based on multi-field coherence achieving much processing gain is a new research direction. We hope that the scientific problems and approaches for the research direction proposed in this paper will guide more researchers to address the topic in order to jointly promote research in this field and obtain more valuable research results in the future.

\section{Acknowledgments}

This work is sponsored by the National Natural Science Foundation of China under Grant No. 61502037 and 61772152, the Basic Research Project No. JCKY2016206B001 and JCKY2016604C010, and Innovation Special zone of National Defense Science and Technology. Project No. 18-H863-05ZT-001-007-02.

\section{References}

1. Parra L, Sendra S, Lloret J, Rodrigues JJ (2017) Design and deployment of a smart system for data gathering in aquaculture tanks using wireless sensor networks. International Journal of Communication Systems 30(16): e3335.

2. Kim H W, Cho H S (2017) SOUNET: Self-Organized Underwater Wireless Sensor Network. Sensors (Basel) 17(2): E0283.

3. Xu C X, Piao S C, Zhang H G, Shi E YANG (2016) Experimental study of sound propagation using a deep-water vector hydrophone. SCIENTIA SINICA Physica, Mechanica \& Astronomica 46(9): 094306.

4. V G Petnikov, V M Kuzkin (2002) Shallow water variability and its manifestation in the interference pattern of sound fields. AIP Conference Proceedings 621(1): 207-217. 
5. Kevin L Cockrell, Henrik Schmidt (2011) A modal Wentzel-KramersBrillouin approach to calculating the waveguide invariant for non-ideal waveguides. J Acoust Soc Am 130(1): 72-83.

6. E C Shang, J R Wu, Z D Zhao (2012) Relating waveguide invariant and bottom reflection phase-shift parameter $\mathrm{P}$ in a Pekeris waveguide. J Acoust Soc Am 131(5): 3691-3697.

7. Kunde Y, Yanyang L, Runze X, Quan S (2018) Transmission characteristics of convergence zone in deep-sea slope. Applied Acoustics 139: 222-228.

8. Shuanglin W, Zhenglin L, \& Jixing Q (2015) Geoacoustic inversion for bottom parameters in the deep-water area of the south china sea. Chin Phys Lett 32(12): 70-73.

9. UdovydchenkovI A, Stephen R A, Duda T F, Bolmer S T, Worcester PF, et al. (2012) Bottom interacting sound at 50?km range in a deep ocean environment. J Acoust Soc Am 132(4): 2224-2231.

10. Ren QY, Piao S C, Zhang HG, Chen F B (2010) Investigation of interference phenomena of vector field in shallow water. Piezoelectricity Acoustic Waves Device Applications IEEE.

11. Kuznetsov G N, Stepanov AN (2015) Interference and phase structure of the low-frequency vector-scalar field in shallow water for variable reception or transmission depths. Physics of Wave Phenomena 23(4): 279-291.

12. SD Chuprov (1982) Interference structure of a sound field in a layered ocean. In: LM Brekhovskikh, IB Andreevoi (Eds.) Acoustics of the Ocean 71-91.

13. Chuanxiu XU, Shengchun P, Haigang Z, Shie Y (2016) Experimental study of sound propagation using a deep-water vector hydrophone. Scientia Sinica.
14. Emmetière Rémi, Julien B, Géhant Marie, Xavier C, Thierry C (2018) Understanding deep-water striation patterns and predicting the waveguide invariant as a distribution depending on range and depth. The Journal of the Acoustical Society of America 143(6): 3444-3454.

15. Petnikov, V G (2002 ocean acoustic interference phenomena and signal processing - san francosco, california (usa) (1-3 May 2001). AIP conference proceedings 621: 207-220.

16. Cockrell KL, Schmidt H (2011) A modal wentzel-kramers-brillouin approach to calculating the waveguide invariant for non-ideal waveguides. J Acoust Soc Am 130(1): 72-83.

17. Shang EC, Wu JR, Zhao Z D (2012) Relating waveguide invariant and bottom reflection phase-shift parameter $\mathrm{p}$ in a pekeris waveguide. J Acoust Soc Am 131(5): 3691-3697.

18. Petukhov Y V, Borodina E L, Burdukovskaya V G (2018) Features of the invariant of the spatial-frequency interference structure of acoustic fields in oceanic waveguides. Acoustical Physics 64(4): 479-491.

19. Raevsky MA, \& Khil'ko A I (2016) Spatial correlation of the lowfrequency acoustic reverberation in oceanic waveguides. Radiophysics and Quantum Electronics 58(12): 934-941.

20. Ma X, Zheng C (2016) Decision fractional fast fourier transform doppler compensation in underwater acoustic orthogonal frequency division multiplexing. The Journal of the Acoustical Society of America 140(5): EL429-EL433.

21. Ma X, Wang T, Lin Y, Jin S (2018) Parallel iterative inter-carrier interference cancellation in underwater acoustic orthogonal frequency division multiplexing. Wireless Personal Communications 102(5).

Your next submission with Juniper Publishers
will reach you the below assets
- Quality Editorial service
- Swift Peer Review
- Reprints availability
- E-prints Service
- Manuscript Podcast for convenient understanding
- Global attainment for your research
- Manuscript accessibility in different formats
( Pdf, E-pub, Full Text, Audio)
- Unceasing customer service
Track the below URL for one-step submission
https://juniperpublishers.com/online-submission.php

